\title{
In situ synchrotron radiation monitoring of phase transitions during microwave heating of $\mathrm{Al}-\mathrm{Cu}-\mathrm{Fe}$ alloys
}

\author{
Sébastien Vaucher ${ }^{a)}$ \\ EMPA, Swiss Federal Laboratories for Materials Science and Technology, \\ CH-3602 Thun, Switzerland \\ Radu Nicula \\ EMPA, Swiss Federal Laboratories for Materials Science and Technology, CH-3602 Thun, \\ Switzerland; and Institute of Physics, University of Rostock, D-18055 Rostock, Germany \\ José-Manuel Català-Civera \\ Polytechnical University of Valencia, School of Telecommunication, Camino de Vera s/n E-46022 \\ Valencia, Spain \\ Bernd Schmitt and Bruce Patterson \\ Swiss Light Source, Paul Scherrer Institute, CH-5232 Villigen, Switzerland
}

(Received 8 June 2007; accepted 24 September 2007)

\begin{abstract}
The effect of rapid microwave heating has so far been evaluated mainly by comparing the state of materials before and after microwave exposure. Yet, further progress critically depends on the ability to follow the evolution of materials during ultrafast heating in real time. We describe the first in situ time-resolved monitoring of solid-state phase transitions during microwave heating of metallic powders using wide-angle synchrotron radiation diffraction. Single-phase $\mathrm{Al}-\mathrm{Cu}-\mathrm{Fe}$ quasicrystal powders were obtained by microwave heating of nanocrystalline alloy precursors at $650{ }^{\circ} \mathrm{C}$ in $<20 \mathrm{~s}$.
\end{abstract}

\section{INTRODUCTION}

Ultrafast heating and cooling are essential to the preservation of nanoscale features in bulk nanostructured solids. Both microwave ${ }^{1}$ and spark plasma-sintering ${ }^{2,3}$ techniques offer feasible manufacturing solutions that will soon be able to be used on an industrial scale. Common to these modern technologies is the kinetic suppression of excessive grain growth during densification. During the past few decades, microwave heating has been successfully used in a broad variety of applications, ranging from rapid food conditioning, to wood processing, sterilization, and drying, to the chemical synthesis and sintering of new materials. ${ }^{4-7}$ Despite efforts to fine tune the use of microwaves to specific applications, there is still a lack of experimental knowledge on the changes materials undergo in their structure, the constitution of phases, morphology, and properties during their exposure to microwave fields. Modern microwave-heating technologies still rely solely on the room-temperature examination of the structure, microstructure, and properties of materials before and after microwave heating. The few previous attempts to follow in situ the evolution of materials during microwave heating ${ }^{8-13}$ were part of the sustained

\footnotetext{
a) Address all correspondence to this author.

e-mail: sebastien.vaucher@empa.ch

DOI: $10.1557 / J M R .2008 .0009$
}

effort to clarify the occurrence and nature of nonthermal contributions to mass transport [i.e., solely due to the application of high-frequency electromagnetic (EM) fields]. ${ }^{714-16}$ The enhancement of atomic diffusion under EM field application is known as the "microwave effect." The experimental validation of the microwave effect is a central topic of modern research on the interaction of materials with microwave fields. Intense efforts were dedicated during the past decade to understanding the role of microwave $\mathrm{E}$ and $\mathrm{H}$ fields on phase transformations. ${ }^{1,17-20}$

So far, the few in situ studies ${ }^{8-10}$ of structural transitions of materials during microwave heating did almost exclusively rely on neutron scattering. A first in situ xray diffraction (XRD) study was performed by Robb et al., ${ }^{11}$ using laboratory x-ray equipment. High heating rates of tens of degrees per second and higher are not unusual in microwave heating. Therefore, the use of high-flux synchrotron radiation and of fast $\mathrm{x}$-ray detectors is essential to in situ real-time diffraction experiments, for which a satisfactory compromise must be reached between the counting statistics and the time resolution. We report on the first in situ microwave heating experiments using wide-angle synchrotron radiation powder diffraction. We focus our present discussion on the in situ time-resolved monitoring of solid-state phase transitions during the microwave heating of quasicrystal (QC)-forming $\mathrm{Al}-\mathrm{Cu}-\mathrm{Fe}$ alloys. 
Contrary to what was believed for many years, microwaves may also be used to process metallic fine powders. ${ }^{20}$ Discovered more than two decades ago in meltspun Al-Mn alloys, ${ }^{21}$ QCs were meanwhile shown to form in over 100 alloy systems. ${ }^{22}$ QCs are nonperiodic, long-range, ordered solids with noncrystallographic rotational symmetries, ${ }^{23}$ and exhibit outstanding properties of major technological interest ${ }^{22-25}$ (e.g., low friction, adherence or wear, high hardness, high strength, low thermal and electrical conductivity, plastic deformation, or biocompatibility). Due to the wider availability of its constituents, $\mathrm{Al}-\mathrm{Cu}-\mathrm{Fe}$ QCs are nearer to industrial applications, ${ }^{26}$ so that recent research efforts have focused on their synthesis and processing on a larger scale. ${ }^{26-28}$

\section{EXPERIMENTAL}

Metallic nanopowders with nominal composition of A162at.\%-Cu25.5at.\%-Fe12.5at.\% were prepared by the wet milling of high-purity elements using a high-energy planetary ball mill (PM 400; Retsch, Haan, Germany). Suitable precursor powders are readily obtained by short milling for 6-10 h using standard stainless-steel milling equipment. ${ }^{28}$

Microwave heating was carried out in a WR-340 waveguide terminated with a sliding short-circuit. The microwave generator with a maximum power of $1.2 \mathrm{~kW}$ at $2.45 \mathrm{GHz}$ (Dipolar AB, Skellefteå, Sweden) is directly coupled to the waveguide. The incident and reflected microwave power is monitored using a high-power impedance analyzer (S-TEAM STHT, Bratislava, Slovakia). The sliding short-circuit was adjusted to ensure that the samples are located at the maximum of the electrical field of the TE10n mode of the empty cavity. Nevertheless, it is likely that in the presence of the capillary loaded with the powder specimen, the field distribution will be distorted and so the sample experiences the action of a mixed $\mathrm{E} / \mathrm{H}$ field. ${ }^{29}$

The in situ experiments were performed at the powderdiffraction station of the Materials Science X04SA wiggler beamline ${ }^{30}$ of the Swiss Light Source (SLS) (Villigen, Switzerland). A photograph of the microwave setup installed at the X04SA beamline is shown in Fig. 1. The beamline optics, comprising two collimation mirrors and a double flat-crystal monochromator, allows for an optimal collimation of the beam to achieve a small beamspot at the sample location. For our experiment, performed using a synchrotron radiation wavelength $\lambda=0.07087 \mathrm{~nm}$, the photon flux was equal to $10^{12}-10^{13}$ photons per second. Conventionally, powder-diffraction measurements are done by scanning a detection system with a few channels over the angular range of interest. Instead, we took advantage of the newly developed MYTHEN microstrip detector, ${ }^{31}$ which employs a massively parallel detection system covering an angular

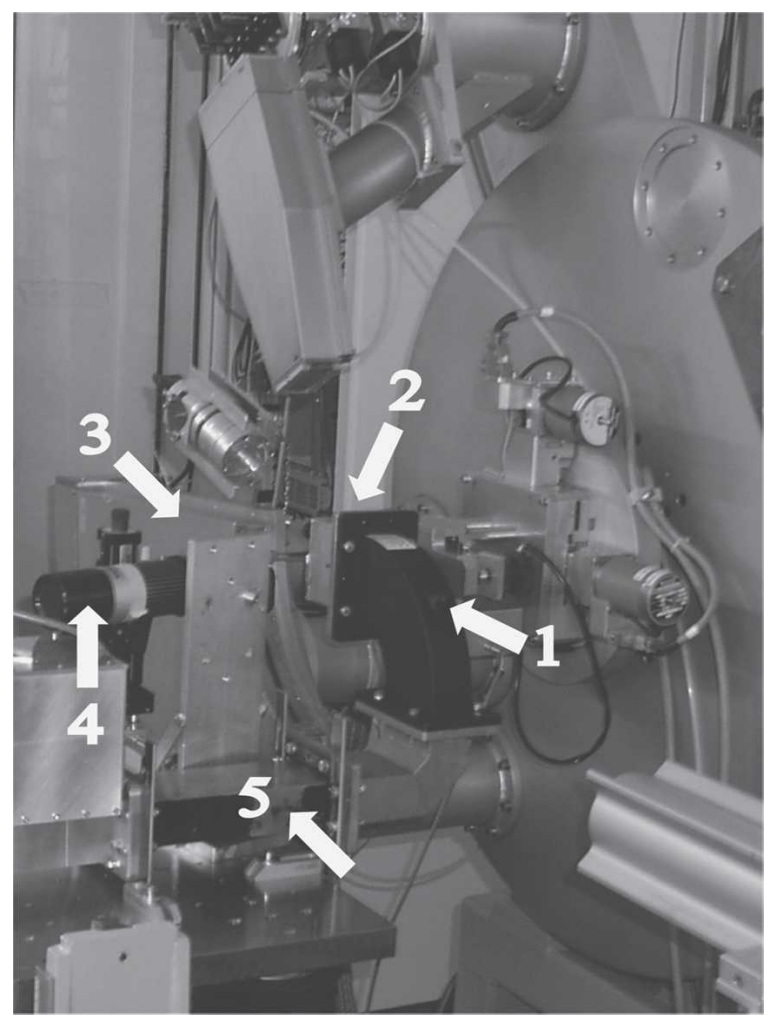

FIG. 1. Portable microwave setup installed at the X04SA beamline at the SLS: (1) X-ray beam path; (2) sample position; (3) Mythen detector; (4) infrared pyrometer; and (5) microwave waveguide.

range of $60^{\circ} 2 \theta$ with 15,000 independent channels. This reduces the full-spectrum measurement time from hours to seconds and below. The time resolution of the present experiment averaged to $4 \mathrm{~s}$ (i.e., fixed exposure time of $1 \mathrm{~s}$, with additional 3-4 s for data transfer).

Dry-powder specimens were mounted into $\varnothing 1$-mm alumina capillaries and inserted into the resonant cavity through a nonradiating slot. The sample temperature was monitored by an optical pyrometer (SXACLS; Raytek, $\mathrm{GmbH}$, Berlin, Germany). Diffraction patterns were also collected on empty capillaries and on standard $\mathrm{LaB}_{6}$ (NIST 660a) powders to determine the x-ray wavelength, the zero-shift, and the instrument-resolution function. The empty capillary spectrum was subtracted from all specimen diffraction patterns. The diffraction patterns of the QC $\psi$-phase were indexed following the formalism of Cahn et al. ${ }^{32}$ using $(\mathrm{N}, \mathrm{M})$ indices. The XRD lines of the icosahedral structure are defined by a pair of scattering vectors in the parallel and perpendicular spaces ${ }^{32}$ :

$$
\begin{aligned}
& Q_{\mathrm{II}}=\frac{1}{a_{Q}} \sqrt{\frac{N+M \tau}{2+\tau}}=\frac{1}{a_{6 D}} \sqrt{\frac{N+M \tau}{2(2+\tau)}}=\frac{2 \sin \theta}{\lambda}, \\
& Q_{\perp}=\frac{1}{a_{Q}} \sqrt{\frac{\tau(N \tau-M)}{2+\tau}}=\frac{1}{a_{6 D}} \sqrt{\frac{\tau(N \tau-M)}{2(2+\tau)}},
\end{aligned}
$$


where $\lambda$ is the $\mathrm{x}$-ray wavelength, $\tau$ is the irrational "golden mean" number, $a_{6 D}$ is the lattice constant of the periodic six-dimensional hypercubic lattice, and $a_{Q}$ is the real space quasi-lattice constant. ${ }^{32}$ The quasi-lattice constants were determined by a least-squares fitting procedure using at least 10 diffraction lines.

\section{RESULTS AND DISCUSSION}

Over 500 high-resolution XRD patterns were collected during the in situ microwave-heating experiment. The microwave-heating profile is shown in Fig. 2. We have simultaneously recorded the pyrometer temperature, the applied microwave power, and the microwave power absorbed by the $\mathrm{Al}-\mathrm{Cu}-\mathrm{Fe}$ powders.

The $\mathrm{Al}-\mathrm{Cu}-\mathrm{Fe}$ powder specimens undergo structural phase transitions only within the regions of interest (ROIs) given by the time intervals $\mathrm{A}$ and $\mathrm{B}$ (gray-shaded regions in Fig. 2). Within region A, the applied microwave power is raised to $42 \mathrm{~W}$. The input microwave power was later increased to $70 \mathrm{~W}$ (region B). The increase in the applied microwave power to $96 \mathrm{~W}$ (elapsed time 1200 to $1300 \mathrm{~s}$ ) does not cause further structural changes. Finally, region $\mathrm{C}$ corresponds to the fast specimen cooling following microwave shut off. We notice that the Al-alloy powders sustain stable microwave heating without thermal runaway or melting over the whole duration of the experiment. There is an immediate response of the specimen to the application of the microwave field and to its removal. The specimen-absorbed microwave power needed to complete the transformation to single-phase QCs is $<10 \mathrm{~W}$.

The as-prepared $\mathrm{Al}-\mathrm{Cu}-\mathrm{Fe}$ powders contain a mixture of cubic $\beta-\mathrm{Al}(\mathrm{Fe})$ solid solution (PDF 85-1327) and $\theta-\mathrm{Al}_{2} \mathrm{Cu}$ (PDF 89-1980, tetragonal) phases, together with residual pure aluminum (PDF 4-0787). The first ROI

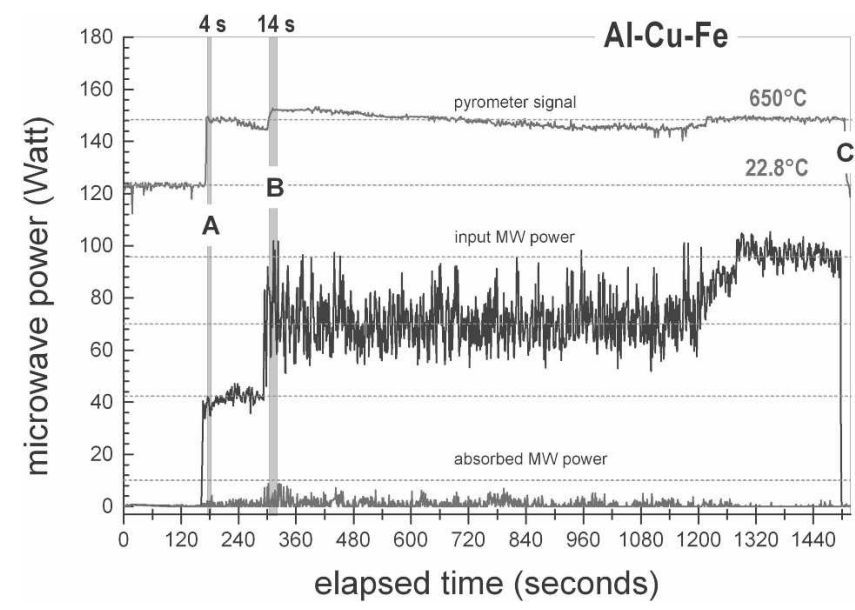

FIG. 2. The microwave heating temperature-time profile. Also shown are the applied and the specimen-absorbed microwave power. (region A, elapsed time from 174 to $178 \mathrm{~s}$ ) comprises a very short time interval of only $4 \mathrm{~s}$, immediately following microwave application (Fig. 3). Within this ROI, the tetragonal $\omega-\mathrm{Al}_{7} \mathrm{Cu}_{2} \mathrm{Fe}$ phase (PDF 3-65-1685) is formed, still coexisting with the initial $\beta-\mathrm{Al}(\mathrm{Fe})$ and $\theta-\mathrm{Al}_{2} \mathrm{Cu}$ phases.

The next ROI (region B, elapsed time 305 to 319 s) comprises the solid-state phase transformations triggered by the rise of the microwave power to $70 \mathrm{~W}$ (Fig. 4). We observe the transformation of the initial $\beta$-phase (Ferich) and $\theta$-phase $\left(\mathrm{Cu}\right.$-rich) to the $\omega-\mathrm{Al}_{7} \mathrm{Cu}_{2} \mathrm{Fe}$ phase [Figs. 4(a)-4(d)], which indicates a gradual homogenization of the alloy composition. ${ }^{27}$ The QC $\psi$-phase starts to form as soon as the tetragonal $\omega-\mathrm{Al}_{7} \mathrm{Cu}_{2} \mathrm{Fe}$ phase becomes the major constituent of the alloy [Fig. 4(d)]. Altogether, the increase of the microwave power to $70 \mathrm{~W}$ (region B) triggers the complete transformation to a single-phase icosahedral QC structure [Figs. 4(c)-4(f)]. The $\omega-\mathrm{Al}_{7} \mathrm{Cu}_{2} \mathrm{Fe}$ phase is the main precursor of the quasicrystalline $\psi$-phase. ${ }^{28}$ The final $\omega \rightarrow \psi$ transition [Figs. 4(d)-4(f)] is completed in $<10 \mathrm{~s}$, while the absorbed microwave power does not exceed $10 \mathrm{~W}$. The QC $\psi$-phase is preserved during the rest of the in situ microwave-heating experiment (Fig. 5). The transformation sequence under microwave irradiation may be summarized as follows (minor phases in brackets):

$$
\begin{aligned}
& \beta-\mathrm{Fe}(\mathrm{Al})+\theta-\mathrm{Al}_{2} \mathrm{Cu}(+\mathrm{Al}) \rightarrow \omega-\mathrm{Al}_{7} \mathrm{Cu}_{2} \mathrm{Fe}(+\theta) \\
& \quad \rightarrow \omega-\mathrm{Al}_{7} \mathrm{Cu}_{2} \mathrm{Fe}+\psi \rightarrow \psi
\end{aligned}
$$

The above sequence of phase transformations does not contradict previous findings. ${ }^{27,28}$ However, the formation of the body-centered cubic $\gamma$-phase $\left(\mathrm{Al}_{4} \mathrm{Cu}_{9}\right.$-type $)$ or of the $\mathrm{Fe}_{3} \mathrm{Al}$ phase was not detected here. The nucleation of these intermediate phases is thus either kinetically suppressed during microwave heating or their transient

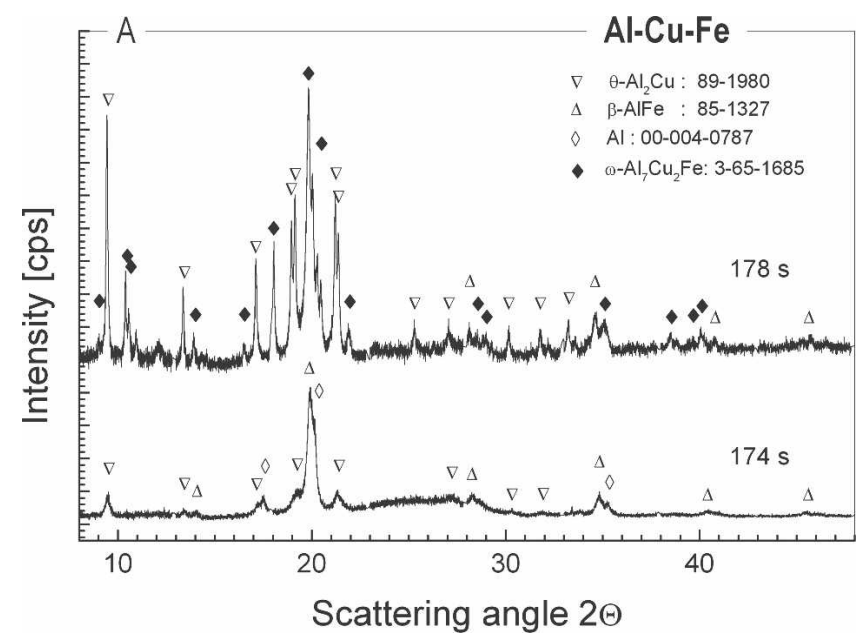

FIG. 3. Phase transitions of the as-prepared AlCuFe powders after microwave application (region A). 


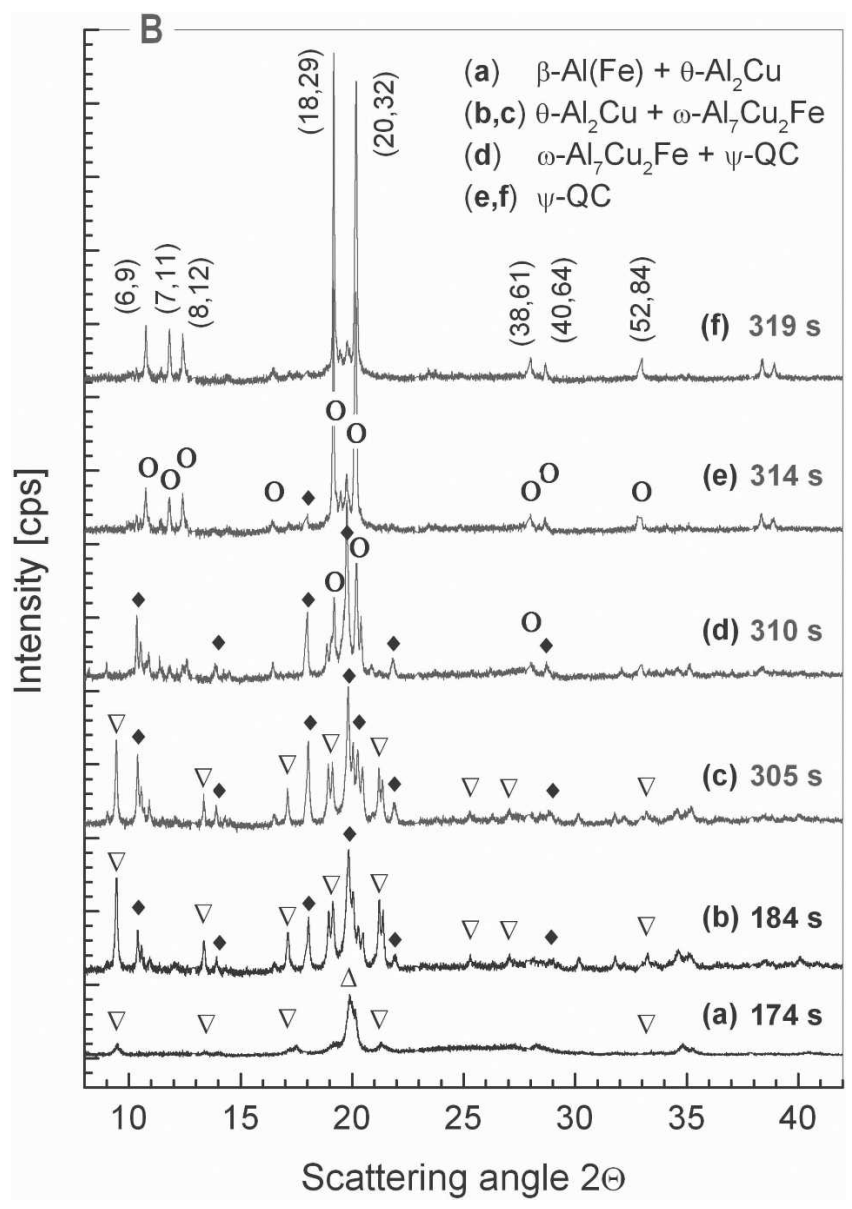

FIG. 4. Sequence of solid-state transitions leading to the formation of single-phase QCs [up triangles $\beta-\mathrm{Fe}(\mathrm{Al})$; down triangles $\theta-\mathrm{Al}_{2} \mathrm{Cu}$; diamonds $\omega-\mathrm{Al}_{7} \mathrm{Cu}_{2} \mathrm{Fe}$; open circles $\psi$-phase).

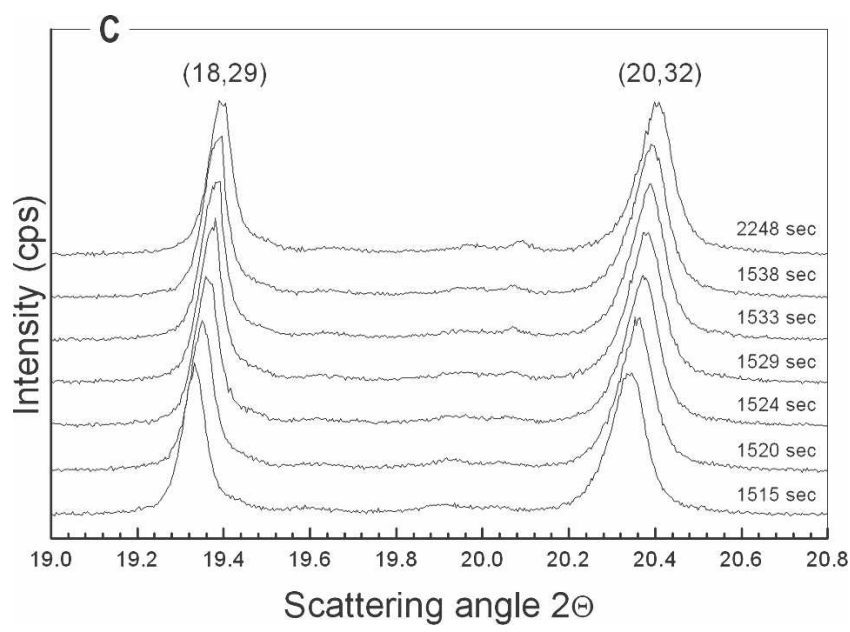

FIG. 5. Shift of the XRD patterns of the icosahedral $\psi$-phase during specimen cooling (region C).

formation cannot be observed with the present time resolution. Another important difference with conventional heating is the spectacular enhancement of the phasetransformation rate upon microwave irradiation. The ki- netics of the $\omega \rightarrow \psi$ phase transition upon isothermal conventional heating was recently investigated by timeresolved XRD using synchrotron radiation. ${ }^{33}$ It was shown that even after $40 \mathrm{~min}$ at $700{ }^{\circ} \mathrm{C}$, only $96 \%$ of the specimen is transformed to the quasicrystalline $\psi$-phase. In contrast, the same transition is completed under microwave irradiation in $<10 \mathrm{~s}$ [Figs. 4(d)-4(f)].

The diffraction patterns of the icosahedral QC $\psi$-phase were indexed following the formalism of Cahn et al. ${ }^{32}$ using $(\mathrm{N}, \mathrm{M})$ indices. All diffraction lines correspond to an F-type icosahedral QC structure. The well-defined triplet of diffraction lines given by the $(6,9),(7,11)$, and $(8,12)$ Bragg reflections [Fig. 4(f)] gives evidence for the formation of a QC structure ${ }^{25,34}$ and not of large unit-cell approximants. ${ }^{35}$ Single-phase QC powders are therefore obtained (Fig. 5). From the evolution of the quasi-lattice constant $a_{Q}$ during cooling (region C), we could estimate the maximum temperature attained during microwave exposure. We assume a parabolic temperature dependence of the quasi-lattice constant:

$$
a_{Q}=a_{0}+\alpha \cdot T+\beta \cdot T^{2},
$$

where $T$ is the absolute temperature, $\alpha$ is the coefficient of thermal expansion, and $\beta=d \alpha / d T$. The coefficients of thermal expansion of the QC $\psi$-phase are known ${ }^{36,37}$ $\alpha=13.18044 \times 10^{-6} \mathrm{~K}^{-1}$ and $\beta=0.25686 \times 10^{-8} \mathrm{~K}^{-2}$ (measured upon cooling of $\mathrm{Al}-\mathrm{Cu}-\mathrm{Fe}$ powders of similar chemical composition). This in turn allows us to determine the temperature-time evolution of the quasi-lattice parameter $a_{\mathrm{Q}}$ of the icosahedral $\psi$-phase during cooling (Fig. 6).

The maximum temperature attained during our in situ experiment (Fig. 2) equals $650{ }^{\circ} \mathrm{C}\left( \pm 20^{\circ} \mathrm{C}\right)$, which is in agreement with previous results. ${ }^{28}$ This further allows for a rough estimation of the cooling rate during microwave treatment, which is found to vary between 45.96 and $23.4^{\circ} \mathrm{C} / \mathrm{s}$ (Fig. 6).

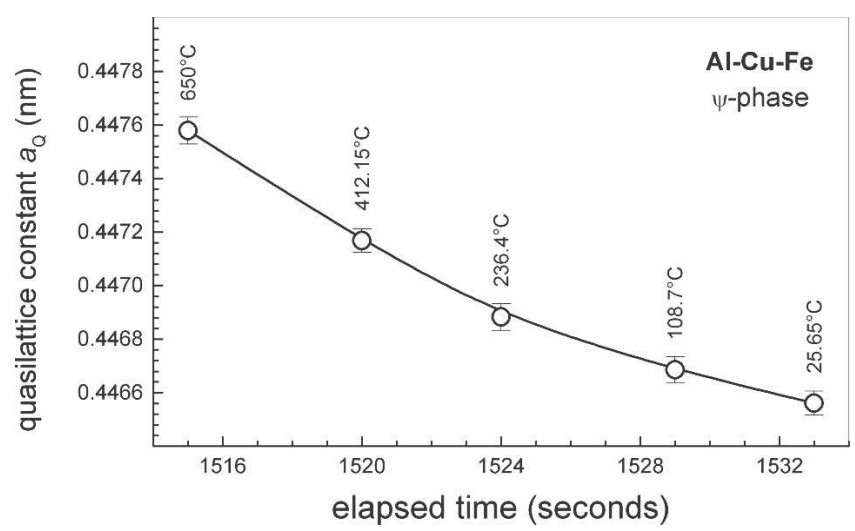

FIG. 6. Quasi-lattice constant of the icosahedral $\psi$-phase during cooling (region $\mathrm{C}$ ). 


\section{CONCLUSIONS}

We have demonstrated here the feasibility and potential advantages of using microwave heating for the synthesis of alloy powders with a complex atomic structure. Single-phase $\mathrm{Al}-\mathrm{Cu}-\mathrm{Fe}$ QC powders were obtained by microwave heating of metallic precursors in $<20 \mathrm{~s}$. High heating $\left(46{ }^{\circ} \mathrm{C} / \mathrm{s}\right)$ and cooling $\left(23{ }^{\circ} \mathrm{C} / \mathrm{s}\right)$ rates were observed. In particular, the high cooling rate is a unique advantage of microwave heating over other powder synthesis/processing methods.

Beyond the ultrafast microwave synthesis of quasicrystalline powders and, even more important, the present work demonstrates that the combined use of highbrilliance synchrotron radiation sources and of fast x-ray detectors enables the in situ real-time observation of the interaction of materials with microwave fields and of its kinetic features. Information yielded by in situ timeresolved experiments will greatly improve our fundamental knowledge on the mechanisms of mass transport and structural phase transitions in the presence of EM fields, as well as our means to fine-tune microwave processing for a broad variety of nanomaterials. Furthermore, opportunities for developing new materials will emerge, with potential implications for powder metallurgy, microwave chemistry, catalysis, pharmacy, food processing, biology, or medicine.

\section{ACKNOWLEDGMENTS}

Radu Nicula gratefully acknowledges Prof. Dr. Eberhard Burkel and Dr. Manuela Stir (Rostock University, Germany) for continuous support.

\section{REFERENCES}

1. R. Roy and D. Agrawal: The new science of microwave-materials interactions: The role of separated e and $\mathrm{h}$ fields and its real world applications, in Proceedings of the 6th Symposium on Microwave Applications and Related Fields, November 2-4, 2006, OyakiCity, Japan.

2. S. Seal, S.C. Kuiry, P. Georgieva, and A. Agarwal: Manufacturing nanocomposite parts: Present status and future challenges. MRS Bull. 29(1), 16 (2004).

3. Z. Shen, Z. Zhao, H. Peng, and M. Nygren: Formation of tough interlocking microstructures in silicon nitride ceramics by dynamic ripening. Nature 417, 266 (2002).

4. J.D. Katz: Microwave sintering of ceramics. Annu. Rev. Mater. Sci. 22, 153 (1992).

5. Materials Research Advisory Board: Microwave Processing of Materials (National Research Council, Publication NMAB-473, National Academy Press, 1994).

6. D.E. Clark, D.C. Folz, C. Folgar, and M. Mahmoud: Microwave Solutions for Ceramic Engineers (The American Ceramics Society ACerS, Inc., Westerville, OH, 2005).

7. Yu.V. Bykov, K.I. Rybakov, and V.E. Semenov: Hightemperature microwave processing of materials. J. Phys. D: Appl. Phys. 34, R55 (2001).

8. A.G. Whittaker, A. Harrison, G.S. Oakley, I.D. Youngson,
R.K. Heenan, and S.M. King: Preliminary experiments on apparatus for in situ studies of microwave-driven reactions by small angle neutron scattering. Rev. Sci. Instrum. 72, 173 (2001).

9. A. Harrison, R. Ibberson, G. Robb, G. Whittaker, C. Wilson, and D. Youngson: In situ neutron diffraction studies of single crystals and powders during microwave irradiation. Faradav Discuss. $\mathbf{1 2 2}$ $363(2002)$

10. M.M. Günter, C. Korte, G. Brunauer, H. Boysen, M. Lerch, and E. Suard: In situ high temperature neutron diffraction study of $\mathrm{Sr} / \mathrm{Mg}$-doped lanthanum gallate superionic conductors under microwave irradiation. Z. Anorg. Allg. Chem. 631, 1277 (2005).

11. G.R. Robb, A. Harrison, and A.G. Whittaker: Temperatureresoved, in-situ powder x-ray diffraction of silver iodide under microwave irradiation. Phys. Chem. Comm. 5, 135 (2002).

12. S. Vaucher, J-M. Catala-Civera, A. Sarua, J. Pomeroy, and M. Kuball: Phase selectivity of microwave heating evidenced by Raman spectroscopy. J. Appl. Phys. 99, 113505 (2006).

13. A. Nesbitt, P. Navabpour, B. Degamber, C. Nightingale, T. Mann, G. Fernando, and R.J. Day: Development of a microwave calorimeter for simultaneous thermal analysis, infrared spectroscopy and dielectric measurements. Meas. Sci. Technol. 15.2313 (2004).

14. S.A. Freeman, J.H. Booske, and R.F. Cooper: Microwave field enhancement of charge transport in sodium chloride. Phvs. Rev. Lett. 74, 2042 (1995).

15. J.H. Booske, R.F. Cooper, and S.A. Freeman: Microwave enhanced reaction kinetics in ceramics. Mater. Res. Innovations $\mathbf{1}$ 77 (1997)

16. K.I. Rybakov and V.E. Semenov: Mass transport in ionic crystals induced by the ponderomotive action of a high-frequency electric field. Phvs. Rev. B 52, 3030 (1995).

17. J. Cheng, R. Roy, and D. Agrawal: Experimental proof of major role of magnetic losses in microwave heating of metal and metallic composites. J.Mater. Sci. Lett. 20, 1561 (2001)

18. R. Roy, P.D. Peelamedu, J.P. Cheng, C. Grimes, and D. Agrawal: Major phase transformations and magnetic property changes caused by electromagnetic fields at microwave frequencies J. Mater. Res. 17(12), 3008 (2002).

19. R. Roy, P.D. Peelamedu, L. Hurtt, J.P. Cheng, and D. Agrawal: Definitive experimental evidence for microwave effects: Radically new effects of separated $\mathrm{E}$ and $\mathrm{H}$ fields, such as decrystallization of oxides in seconds. Mater. Res. Innovations 6, 128 (2002).

20. R. Roy, D. Agrawal, J. Cheng, and S. Gedevanshvili: Full sintering of powdered-metal bodies in a microwave field. Nature 399 $668(1999)$

21. D. Shechtman, I. Blech, D. Gratias, and J. Cahn: Metallic phase with long range orientational order and no translational symmetry. Phvs. Rev. Lett. 53, 1951 (1984).

22. H-R. Trebin, ed.: Quasi-crystals (Wiley-VCH, Weinheim, 2003).

23. Chr. Janot: The properties and applications of quasi-crystals. Europhys. News 27, 60 (1996).

24. D.J. Sordelet and J.M. Dubois, ed.: Quasi-crystals. MRS Bull. 22(11), (1997).

25. J.M. Dubois: Useful Quasi-crystals (World Scientific Publishing, Singapore, 2003).

26. E. Huttunen-Saarivirta: Microstructure, fabrication and properties of quasi-crystalline $\mathrm{Al}-\mathrm{Cu}-\mathrm{Fe}$ alloys: A review. 363, 150 (2004).

27. V.V. Tcherdyntsev, S.D. Kaloshkin, A.I. Salimon, E.A. Leonova, J. Eckert, F. Schurack, V.D. Rogozin, S.P. Pisarev, and Y.P. Trykov: Al-Cu-Fe quasi-crystalline phase formation by mechanical alloying. Mater. Manufact. Proc. 17. 825 (2002).

28. R. Nicula, M. Stir, F. Turquier, and E. Burkel: Single-phase bulk $\mathrm{Al}-\mathrm{Cu}-\mathrm{Fe}$ quasi-crystals by field-assisted sintering. Mater. Sci. Eng., $A$ (doi:10.1016/j.msea.2007.01.163, in press). 
29. D.C. Dube, P.D. Ramesh, J. Cheng, M.T. Lanagan, D. Agrawal, and R. Roy: Experimental evidence of redistribution of fields during processing in a high-power microwave cavity. Appl. Phvs. Lett. 85(16), 3632 (2004).

30. B.D. Patterson, Ch. Brönnimann, D. Maden, F. Gozzo, A. Groso, B. Schmitt, M. Stampanoni, and P.R. Wilmott: The materials science beamline at the Swiss Light Source. Nucl. Instrum. Methods Phys. Rev. Sect. B 238, 224 (2005).

31. B. Schmitt, Ch. Brönnimann, E.F. Eikenberry, F. Gozzo, C. Hörmann, R. Horisberger, and B. Patterson: Mythen detector system. $\mathrm{Nucl}$. Instrum. Methods Phvs. Rev., Sect. A 501, 267 (2003).

32. J.W. Cahn, D. Shechtman, and D. Gratias: Indexing of icosahedral quasiperiodic crystals. J. Mater. Res. 1, 13 (1986).

33. E. Otterstein, R. Nicula, J. Bednarcik, M. Stir, and E. Burkel: In situ time-resolved $\mathrm{X}$-ray diffraction investigation of the $\omega \rightarrow \psi$ transition in $\mathrm{Al}-\mathrm{Cu}-\mathrm{Fe}$ quasi-crystal-forming alloys. Mater. Sci. Forum 558-559, 943 (2007).

34. Chr. Janot: Quasi-crystals: A Primer (Oxford University Press, New York, 1992).

35. M. Quinquandon, A. Quivy, J. Devaud, F. Faudot, S. Lefebvre, M. Bessiere, and Y. Calvayrac: Quasi-crystal and approximant structures in the $\mathrm{Al}-\mathrm{Cu}-\mathrm{Fe}$ system. J. Phys.: Condens. Matter $\mathbf{8}$. 2487 (1996)

36. A. Quivy, S. Lefebvre, J.L. Soubeyroux, A. Filhol, and R.M. Ibberson: High-resolution time-of-flight measurements of the lattice parameter and thermal expansion of the icosahedral phase $\mathrm{Al}_{62} \mathrm{Cu}_{25.5} \mathrm{Fe}_{12.5}$. J. Appl. Crvstallogr. 27. 1010 (1994).

37. A.M. Korsunsky, A.I. Salimon, I. Pape, A.M. Polyakov, and A.N. Fitch: The thermal expansion coefficient of mechanically alloyed $\mathrm{Al}-\mathrm{Cu}-\mathrm{Fe}$ quasi-crystalline powders. Scripta Mater. 44. 217 (2001). 